Western North American Naturalist 68(1), (C) 2008, pp. 8-14

\title{
AMERICAN PIKAS (OCHOTONA PRINCEPS) IN NORTHWESTERN NEVADA: A NEWLY DISCOVERED POPULATION AT A LOW-ELEVATION SITE
}

\author{
Erik A. Beever ${ }^{1,5}$, Jenifer L. Wilkening 2 , Donald E. McIvor ${ }^{3}$, Shana S. Weber ${ }^{4}$, and Peter F. Brussard ${ }^{2}$
}

\begin{abstract}
The central tenet of island biogeography theory-that species assemblages on islands are functions of island area, isolation from mainlands, and vicariance-has been altered by the demonstrable effects that rapid climate change is imposing on insular faunas, at least in isolated mountaintops. Although populations of American pikas (Ochotona princeps) continue to suffer extirpations, and although the lower bounds of the pika's elevational distribution are shifting upslope across the Great Basin, we report here on the new discovery of a low-elevation population of pikas in a mountain range from which they had not been reported previously. This discovery, particularly in the context of relatively rapid ecological change, highlights the importance of seeking out original sources of information and performing spatially extensive fieldwork. Results presented here further illustrate that although thermal influences appear to be the single strongest determinant of pika distribution currently, such influences interact with a number of other factors to determine persistence.
\end{abstract}

Key words: Bromus tectorum, double sampling, hay piles, Ochotona princeps, rapid climate change, remote temperature recorders.

During warming periods (such as from the late Pleistocene to the present, but especially during the "altithermal" period of the middle Holocene), the distribution of many valleydwelling vertebrates has shifted northward, whereas the distributions of most montane species have shifted upward (Rickart 2001, Beever et al. 2005, Grayson 2005, 2006, Guralnick 2007). In recent decades, the distributions of many montane species have moved upslope, coincident with a relatively small $\left(0.6^{\circ} \mathrm{C}\right)$ increase in global temperature (Beever et al. 2003, Parmesan and Yohe 2003, Walther et al. 2005, Wilson et al. 2005, IPCC 2007, Beever et al. in preparation). This temperature increase is relatively minor compared to the $1.1^{\circ}-6.4^{\circ} \mathrm{C}$ rise predicted globally by the end of the 21 st century (IPCC 2007). For montane species that are truly insularized from neighboring montane habitat "islands" by low-elevation intervening valleys (e.g., montane mammals of the Great Basin), continued temperature increases will likely push upslope and effectively shrink the extent of their mountaintop habitat "islands" (McDonald and Brown 1992).

The American pika (Ochotona princeps Richardson) is an obligate resident of talus and talus-like habitats with cool, moist microclimates across western North America (Smith and Weston 1990, Verts and Carraway 1998). Grayson (2005) found that the rise in minimum elevation of pika populations since historic times (described in Beever et al. 2003) represents the continuation (albeit at a much more rapid pace) of upslope shift of pika distributions in the Great Basin since the late Wisconsinian age. Along with a temperaturedriven distribution, pikas have exhibited extreme vulnerability to elevated temperatures in thermal experiments (MacArthur and Wang 1973, Smith 1974). Also, pikas have been reported to exhibit island-biogeographic, metapopulation, and source-sink dynamics (Brown 1971, Smith and Gilpin 1997, Lawlor 1998, Moilanen et al. 1998, Kruezer and Huntly 2003), and they have been a model used to test extinction theory (McDonald and Brown 1992, Hafner 1994). Extensive sampling has indicated that the distribution of pikas is 1 of the most obligately montane of any mammal in the Great Basin (Lawlor 1998, Rickart 2001: fig. 2).

Observations of pikas have been recorded in the Great Basin since at least the early 20th

\footnotetext{
${ }^{1}$ U.S. National Park Service, Great Lakes Network, Ashland, WI 54806.

${ }^{2}$ Department of Biology, University of Nevada, Reno, NV 89557.

${ }^{3}$ National Audubon Society, 129 Old Twisp Hwy., Twisp, WA 98856.

${ }^{4}$ Princeton University, Office of Sustainability, Princeton, NJ 08543.

5Present address: USGS Alaska Science Center, 4210 University Dr., Anchorage, AK 99508. E-mail: ebeever@usgs.gov
} 
century (Grinnell 1917, Anthony 1924). Using historic (1898-1990) records of pikas in the basin, Beever et al. (2003) documented likely extirpation at 6 of 25 sites with precisely described locations of historic pika presence and posited "functional extirpation" at a 7th site where few pikas were detected. These 6 sites included all known locations of $O . p$. schisticeps within the state of Nevada. Information-theoretic analyses suggested that these losses resulted from climatic factors combined with biogeographic and anthropogenic influences. Furthermore, at several locations where pikas persisted, the minimum elevation of pika occurrence had risen. Surveys across the basin of 27 additional mountain ranges with no historical records also failed to detect pikas (Beever et al. 2003). Resurveys of the original 25 historic sites during 2003-2007 (Beever et al. in preparation) suggest that pikas now appear to have been extirpated from more than just 6 sites and that the minimum elevational distribution at many sites where pikas are extant continues to move upslope. These results are corroborated by resurveys of J. Grinnell's extensive and thorough surveys of the adjacent Sierra Nevada nearly a century ago. Resurveys during 2003-2005 of sites in the Sierra Nevada inventoried originally during 19141920 by Grinnell similarly suggest that pika distributions had retracted $>180 \mathrm{~m}$ upslope (E. Rubidge, U.C. Berkeley, unpublished data).

In the Great Basin and elsewhere, several investigators have shown that the strength of island-biogeographic theory and other ecological relationships is predicated upon extensive fieldwork (Brown 1971, Grayson and Livingston 1993, Lawlor 1998, Rickart 2001). In the 1st published summary of pika distribution across much of the Great Basin, Hall (1946:590) provided very precise descriptions of pika geographic range, except in northwestern Nevada (O. p. schisticeps). For this region, he stated, "Probably the animals are much more widely distributed in northwestern Nevada than our 3 records of occurrence indicate." In spite of this statement $>60$ years ago, we are not aware of any surveys that have been conducted in this region to document new locations of pikas.

Here we briefly report on the discovery and confirmation of pikas from the Hays Canyon Range (Washoe Co.) in the northwestern portion of the basin, and discuss implications of that discovery. To understand and interpret the discovery, we compare the thermal characteristics of talus microsites in the range with microsites at other locations of extant and recently extirpated pika populations. Furthermore, we report extensive haying of Bromus tectorum L. (cheatgrass) by pikas at this site and briefly discuss the implication of pikas utilizing this introduced species. Finally, we emphasize the importance of going back to original sources of information (e.g., field notes, old publications; Frey and Malaney 2006) and of extensive empirical fieldwork prior to drawing biogeographic conclusions (sensu Grayson and Livingston 1993).

\section{Methods}

In March 2006, EAB became aware of an anecdotal report that DEM had observed pikas while conducting bird surveys in the Hays Canyon Range in 2002. EAB and SSW visited the sighting location on 6 August 2006 and searched extensively to determine the maximum and minimum elevation at which the species occurred within $3 \mathrm{~km}$ of the 2002 sighting. Field methods followed those reported in Beever et al. (2003). We walked line transects approximately $15 \mathrm{~m}$ apart and searched for any evidence of current pika occupation (i.e., sighting, vocalization, or active hay piles; we searched with higher intensity in locations with fresh fecal pellets). For unoccupied talus patches and locations where we detected pika evidence, we recorded elevation, aspect, average slope gradient, number of potential pika home ranges (each represented as a circle with a diameter of $20 \mathrm{~m}$ ) within the talus patch, and a visual cover estimate of the 5 plant species with greatest areal extent within a $10-\mathrm{m}$ radius. On talus patches elsewhere in the basin, we have found that these visual estimates more frequently detect rare, patchily distributed plants than sampling with line-intercept transects and that these estimates are strongly correlated to transect-derived estimates of plant cover (Beever unpublished data). Position and elevation were obtained with a WAAS-enabled GPS unit (eTrex LegendCx; Garmin International, Olathe, KS), providing accuracy of 3-7 m. Within unoccupied talus patches, data were collected at a randomly selected point within the talus. We used the same criteria as did Beever et al. (2003) to establish the presence of $>1$ individual in a 
localized area, except that paired-observer distance sampling (Buckland et al. 2004) was used to quantify detectability (and in subsequent analyses to obtain density estimates) of individual pikas in the taluses that we searched during the standard 8-hour search period. EAB and SSW searched 14 patches containing enough talus area for 67 home ranges. Given the apparently small size and uniqueness of the population and its potential vulnerability to climate and other influences, we did not collect voucher specimens of pika individuals, but instead collected fecal pellets and photographed hay piles and individuals.

JLW first confirmed the presence of American pikas near the vicinity of the original 2002 sighting on 15 June 2006. In order to measure microsite temperatures where we found pika evidence, she placed 6 remote temperature recorders (DS1921G Thermochron i-Buttons, Maxim Integrated Products, Sunnyvale, CA) $80 \mathrm{~cm}$ below the talus surface in talus patches exhibiting evidence of pikas. These devices continuously recorded temperature at 2-hour intervals for 4 months, until they were picked up on 15 October 2006. Data were obtained from the recorders using a 1-wire adapter and an i-Button TMEX (Dallas Semiconductor, Dallas, TX), and thermal summaries were performed in Microsoft Excel. We considered each recorder as an independent descriptor of temperature within a given site, such as this one. We report here only values pertinent to the Hays Canyon Range and quantify how these values rank among values from other sites across the basin. Mean temperatures for occupied and unoccupied taluses across the basin will be reported elsewhere (Beever et al. in preparation). On 18 July 2006, JLW measured the volume of plant species present in each of all 5 hay piles that she detected near the original record of pikas (Appendix I). As a comparison, she recorded all plant species that occurred in line-point transects within 25 $\mathrm{m}$ of sampled talus patches.

\section{RESUlTS}

On 15 June and 6 August 2006, we recorded multiple sightings of individuals, fresh hay piles, and pika vocalizations, and we detected and collected fresh fecal pellets throughout the site. EAB and SSW documented positive evidence of $\geq 16$ individuals during an 8 - hour period on 6 August 2006, at elevations from 1914 to $2136 \mathrm{~m}$. Additionally, we found an apparently abandoned hay pile at $2212 \mathrm{~m}$. Patch saturation (the number of animals detected per unit area of correctly sized talus) was the 3rd-highest of all populations we have studied in the Great Basin (Beever et al. in preparation). Of the 16 individuals detected during double sampling, EAB and SSW each detected 15 individuals (14 in common). Thus, high (93.3\%) detectability of pikas from these surveys suggests that there were $16.1 \pm 0.5$ individuals within our sampled area. Our 1st detection occurred $<10$ minutes after our arrival at the 1st occupied talus, consistent with detectability results of pikas from across the basin (Beever unpublished data).

Average temperatures during 15 June-31 September 2006 recorded by i-Buttons at Hays Canyon within taluses were remarkably high compared to temperatures at pika-occupied taluses in the rest of the Great Basin. Summer temperatures in occupied taluses at Hays Canyon $\left(\bar{x}=17.33^{\circ} \mathrm{C}[s=1.46]\right.$, range $15.26^{\circ}-$ $19.22^{\circ} \mathrm{C}$ ) averaged from $0.54^{\circ}$ to $12.27^{\circ} \mathrm{C}$ hotter than temperatures within occupied taluses at all other sites in the basin where pikas are extant. Furthermore, the summer temperatures at Hays Canyon averaged $5.1^{\circ} \mathrm{C}$ higher than 1 of the 6 sites at which Beever et al. (2003) failed to detect pikas (Duffer Peak, which reportedly possessed the same subspecies of pika, O. p. schisticeps, as found in Hays Canyon [Hall 1946]), and $0.29^{\circ}-2.10^{\circ} \mathrm{C}$ higher than average temperatures at the sites from which pikas have been extirpated since 1999 (Beever et al. in preparation). Only 1 site that currently contains pikas (Pinchot Creek, White Mountains) registered an average of within-talus temperatures higher than that at Hays Canyon, and it was only $0.23^{\circ} \mathrm{C}$ higher. Although pikas remain in the vicinity (i.e., within $3 \mathrm{~km}$ ) of the historic site at Pinchot Creek, pikas have been lost from the locations where they were recorded historically and during the 1990s, and their extremely low density at the site meant that we were not able to record temperatures within an occupied talus. In addition to these site-level differences, only 3 of 63 i-Buttons across the basin in pika-occupied taluses recorded average temperatures higher than any but the coolest i-Button at Hays Canyon. That is, the 4 warmest of the 5 i-Buttons in 
occupied patches at Hays Canyon experienced warmer average temperatures than 60 of the 63 i-Buttons in pika-occupied taluses across the basin. Of the 86 i-Buttons in unoccupied taluses across the basin, $47 \%$ recorded average temperatures lower than the 4 warmest of the 5 i-Buttons within occupied taluses at Hays Canyon. Among the remaining 53\% of i-Buttons in unoccupied taluses, however, only 2 $(4.3 \%)$ were within the current elevational distribution of pikas at a site that contained at least some pikas.

The hay piles detected at Hays Canyon were some of the largest that EAB has observed above the talus surface in the basin during the last 14 years; maximum volume was about $0.1-0.3 \mathrm{~m}^{3}$. On 18 July, the 5 hay piles detected by JLW contained parts from a combined total of $\geq 21$ plant species (Appendix 1), which constituted a high proportion $(75 \%)$ of the 28 species observed by JLW at the site (Appendix 2). Cheatgrass, Bromus tectorum, which has not previously been reported in a pika hay pile, was the 4th- or 5th-most abundant plant species in all but 1 of the hay piles (Appendix 1).

\section{Discussion}

Against the backdrop of continuing losses of pika populations from the Great Basin and adjacent ecosystems (Beever et al. 2003, J. Patton et al. unpublished report, Beever et al. in preparation), this new discovery of $O$. princeps in the Hays Canyon Mountain Range is important for several reasons. The efforts of Beever et al. (2003) and subsequent surveys failed to detect pikas at all 3 known historical locations of $O$. princeps schisticeps within Nevada, suggesting that the subspecies no longer exists in the state. Although the distribution for O. p. schisticeps in Hall's (1946) map was more continuous than the distributions of any of the other 4 subspecies in the state, pikas had not been reported from the region. Similarly, pikas have not been detected in thorough searches for the species in other Great Basin mountain ranges, including those ranges identified in table 1 and figure 1 of Beever et al. (2003) and in an additional 20 ranges searched for pikas during 1993-1996 (C. Ray personal communication). These searches further underscore the rarity of this species in the Great Basin and suggest that pikas may be detected from at most only a handful of additional "new” ranges.

Pikas, which exhibit a high degree of philopatry and are active year-round (reviewed in Smith and Weston 1990), are highly detectable (in our sampling here, $p=93.3 \%$ ) for these and several other reasons. For human surveyors, it helps that pikas are active diurnally and crepuscularly. Furthermore, pikas use vocalizations for up to 7 functions, including territory defense, and thus quickly communicate their presence and approximate location at a site to investigators. Finally, pikas "cure" vegetation in visibly obvious hay piles. Given these life-history characteristics of pikas, the lack of previous evidence of pikas in the Hays Canyon Range likely reflects the fact that the range was not previously surveyed explicitly for pikas.

Persistence of pikas in the Hays Canyon Range challenges some of the predictions that resulted from the work of Beever et al. (2003), who found that persistence was best explained by a combination of amount of habitat present, a climatic surrogate (i.e., maximum local elevation of talus to which pikas could migrate), and anthropogenic influences (i.e., presence of grazing and proximity to primary roads). The Hays Canyon site has been grazed for most of the past half-century, though apparently not at high stocking rates. In addition, there is little talus habitat in the mountain range, and the maximum elevation of the range is only 2412 m. Furthermore, the total number of potential home ranges in the vicinity $(n=67)$ is the 6 th lowest in the basin. Three of the 5 sites with less habitat have had pikas extirpated altogether, and the other 2 both contain only a few pikas (Beever et al. 2003, Beever et al. in preparation).

Although several lines of evidence (e.g., variable weights from models tested by Beever et al. 2003) suggest that thermal influence may be the single strongest influence on persistence of pikas in the Great Basin, our results here suggest that temperature is not a perfect predictor of persistence. Instead, temperature interacts with a variety of other factors to influence persistence. This is consistent with the conclusion of Thomas et al. (2006: 416), who stated that " . . . multi-factor causes of extinction are likely to be typical" in response to rapid climate change. As an illustration, temperatures at pika-occupied taluses at Hays Canyon averaged higher (rather than lower) 
than temperatures at several sites from which pikas have been extirpated, and higher than temperatures within tens of unoccupied taluses at pika-extant sites across the basin.

Given regional trends and these apparent distributional inconsistencies, pikas in this range would seem to be at least theoretically vulnerable to future extirpation. Given the relationship between latitude and minimum elevation (Grinnell 1917) that existed among extant pika populations after the completion of the resampling of Great Basin pika populations (Beever et al. in preparation), pikas at this latitude in the basin are predicted to occur no lower than $407 \mathrm{~m}$ above the lowest elevation at which they were detected.

As has been our experience across the basin, we detected pikas within 10 minutes of arriving at the occupied talus patch. This detection underscores the contention of Grayson and Livingston (1993) that the understanding of the biogeography of pikas and many other montane mammals of the Great Basin will continue to evolve with additional spatially extensive searches by experienced biologists, especially for species with such high detectability. Such findings may argue for concerted effort to complete spatially extensive surveys of easily detectable species across entire ecoregions in order to provide a better template against which to measure distributional shifts in the face of rapid climate change (Frey and Malaney 2006). In designing such surveys, the implications of rapid climate change (e.g., McDonald and Brown 1992, Skaggs and Boeklen 1996, Beever et al. 2003) suggest that long-standing practices of biogeographic theory (e.g., lumping of several adjacent mountain ranges into a single "sampling" unit to interpret occupancy patterns in montane mammals) may not currently hold true for all species. Instead, at least for the most montane species such as pikas, occupancy patterns in the Great Basin may be better described by considering each site as independent. Furthermore, ecological-niche modeling should be merged with paleontological understanding of distributional changes that have occurred over long timescales (e.g., Grayson 2005, 2006), to predict distributional responses to rapid climate change.

Finally, we were surprised by the large size of hay piles, because relatively low-elevation pika populations in the basin and adjacent ecosystems that have been observed during
1994-2006 have small or undetectable amounts of above-talus hay pile material. Hay piles were rarely detected during extensive surveys performed in 2004-2006 at Lava Beds National Monument, a low-elevation complex of lava flows that averages 1.08 times higher maximum daily temperatures during June-August and only $76 \%$ of the annual precipitation of the extirpated pika sites in the Great Basin. When hay piles were detected there, visible material was usually $<0.01-0.02 \mathrm{~m}^{3}$ in volume (Ray and Beever in preparation). Similarly, Simpson (2001), after hundreds of hours of behavioral observation of pikas at 4 sites in the Columbia River Gorge, reported never being able to find hay piles at his sites despite concerted searches deep into the talus. Given that hay piles purportedly provide sustenance for overwinter survival (Dearing 1997) and given the relative lack of snow cover at sites in the Hays Canyon Range relative to the rest of the pika sites in the basin, we predicted that hay piles at this site would be inauspicious. However, long-term research on pikas in the eastern edge of the Sierra Nevada (Bodie, CA) suggests that the size of hay pile above the talus does not necessarily correlate with the total amount of food stored by pikas (i.e., some to all of it is stored under the talus), and that there is large variability among individuals in hay pile size that is not attributable to elevation (A.T. Smith personal communication). Further investigation is required to establish the generality of these various observations.

Pika's haying of Bromus tectorum also merits mention. Generally, the elevational distribution of B. tectorum is below the lower elevational limit of pika distributions in the Great Basin. Pikas exhibit ecosystem engineering behavior nearest their center of activity and can move plant parts tens of meters (Huntly 1987, Aho et al. 1998, Roach et al. 2001). Furthermore, cheatgrass seeds can germinate even after the mature plant is uprooted or its stem is cut, or after seeds pass through an herbivore's digestive system. Thus, pikas may alter the dynamics of the spread of cheatgrass at local spatial scales. Furthermore, although cheatgrass is a relatively nutritious food plant for herbivores in its earliest phenological stages, in later stages it presents mechanical difficulties for digestion and has low nutritional value for herbivores (Klemmedson and Smith 1964). These relationships may represent another 
stressor for pika populations (both directly through energetic effects and indirectly by alteration of fire cycles; D'Antonio and Meyerson 2002), potentially acting synergistically with other influences; we advocate more-concerted investigations to clarify these relationships.

\section{ACKNOWLEDGMENTS}

Special thanks go to S. Merideth, M. Peacock, C. Ray, A. Smith, and 1 anonymous reviewer for providing reviews of earlier drafts, and to the Nevada Biodiversity Initiative for providing funding. A. Bies provided field assistance to JLW during 2006.

\section{Literature Cited}

Aho, K., N. Huntly, J. Moen, and T. Oksanen. 1998. Pikas (Ochotona princeps: Lagomorpha) as allogenic engineers in an alpine ecosystem. Oecologia 114:405-409.

Anthony, H.E. 1924. Field book of North American mammals. G.P. Putnam's Sons, New York.

Beever, E.A., P.F. Brussard, and J. Berger. 2003. Patterns of extirpation among isolated populations of pikas (Ochotona princeps) in the Great Basin. Journal of Mammalogy 84:37-54.

Beever, E.A., D.A. Pyke, J.C. Chambers, F. Landau, and S. Sмiтh. 2005. Monitoring temporal change in riparian vegetation of Great Basin National Park. Western North American Naturalist 65:382-402.

Brown, J.H. 1971. Mammals on mountaintops: nonequilibrium insular biogeography. American Naturalist 105:467-478.

Buckland, S.T., D.R. Anderson, K.P. Burnham, J.L. LaAKe, D.L. Borchers, and L. Thomas. 2004 Advanced distance sampling: estimating abundance of biological populations. Oxford University Press, New York.

D'Antonio, C., And L.A. Meyerson. 2002. Exotic plant species as problems and solutions in ecological restoration: a synthesis. Restoration Ecology 10:703713.

Dearing, M.D. 1997. The function of haypiles of pikas (Ochotona princeps). Journal of Mammalogy 78:11561163.

Frey, J.K., AND J.L. Malaney. 2006. Snowshoe hare (Lepus americanus) and mountain cottontail (Sylvilagus nuttallii) biogeography at their southern range limit. Journal of Mammalogy 87:1175-1182.

Grayson D.K. 2005. A brief history of Great Basin pikas. Journal of Biogeography 32:2103-2111.

. 2006. The Late Quaternary biogeographic histories of some Great Basin mammals (western USA). Quaternary Science Reviews 25:2964-2991.

Grayson D.K., and S.D. Livingston. 1993. Missing mammals on Great Basin mountains: Holocene extinctions and inadequate knowledge. Conservation Biology 7:527-532.

GrinnelL, J. 1917. Field tests of theories concerning distributional control. American Naturalist 51:115-128.

Guralnick, R. 2007. Differential effects of past climate warming on mountain and flatland species distributions: a multispecies North American mammal assessment. Global Ecology and Biogeography 16:1423.

Hafner, D.J. 1994. Pikas and permafrost: post-Wisconsin historical zoogeography of Ochotona in the southern Rocky Mountains, U.S.A. Arctic and Alpine Research 26:375-382.

HaLl, E.R. 1946. Mammals of Nevada. University of California Press, Berkeley.

HunTLY, N.J. 1987. Influence of refuging consumers (pikas: Ochotona princeps) on subalpine meadow vegetation. Ecology 68:274-283.

[IPCC] Intergovernmental Panel on Climate Change. 2007. Climate change 2007: the physical science basis. Summary for policymakers, fourth assessment report, working group I. Available from: http://www ipcc.ch

Klemmedson, J.O., And J.G. Smith. 1964. Cheatgrass (Bromus tectorum). Botanical Review 30:226-262.

Kruezer, M.P., And N.J. Huntly. 2003. Habitat-specific demography: evidence for source-sink population structure in a mammal, the pika. Oecologia 134:343349 .

LAWLOR, T.E. 1998. Biogeography of Great Basin mammals: paradigm lost? Journal of Mammalogy 79:1111-1130.

MacArthur, R.A., and L.C.H. Wang. 1973. Physiology of thermoregulation in the pika, Ochotona princeps. Canadian Journal of Zoology 51:11-16.

McDonald, K.A., AND J.H. BRown. 1992. Using montane mammals to model extinctions due to global change. Conservation Biology 6:409-415.

Moilanen, A., A.T. Smith, And I. Hanski. 1998. Longterm dynamics in a metapopulation of the American pika. American Naturalist 152:530-542.

Parmesan, C., and G. Yohe. 2003. A globally coherent fingerprint of climate change impacts across natural systems. Nature 421:37-42.

RicKART, E.A. 2001. Elevational diversity gradients, biogeography, and the structure of montane mammal communities in the intermountain region of North America. Global Ecology and Biogeography 10:77100.

Roach, W.J., N. Huntly, and R. Inouye. 2001. Talus fragmentation mitigates the effects of pikas, Ochotona princeps, on high alpine meadows. Oikos 92:315-324.

SKagGS, R.W., AND W.J. BoEkLEN. 1996. Extinctions of montane mammals reconsidered: putting a globalwarming scenario on ice. Biodiversity and Conservation 5:759-768.

SimpSON, W. 2001. Foraging activities of the pika (Ochotona princeps): a comparison of two populations. Master's thesis, Portland State University, Portland, OR.

SMith, A.T. 1974. The distribution and dispersal of pikas: influences of behavior and climate. Ecology 55:13681376.

SMith, A.T., AND M. GiLPIn. 1997. Spatially correlated dynamics in a pika metapopulation. Pages 407-428 in I. Hanski and M. Gilpin, editors, Metapopulation biology: ecology, genetics and evolution. Academic Press, London.

Smith, A.T., And M.L. Weston. 1990. Ochotona princeps. Mammalian Species 352:1-8.

Thomas, C.D., A.M.A. Franco, and J.K. Hill. 2006. Range retractions and extinction in the face of climate warming. Trends in Ecology and Evolution 21:415-416. 
VerTs, B.J., and L.N. Carraway. 1998. Land mammals of Oregon. University of California Press, Berkeley.

Walther, G., S. Beissner, and C.A. Burga. 2005. Trends in the upward shift of alpine plants. Journal of Vegetation Science 16:541-548.

Wilson, R.J., D. GutiérRez, J. GutiérRez, D. Martínez, R. Agudo, and V.J. Monserrat. 2005. Changes to the elevational limits and extent of species ranges associated with climate change. Ecology Letters 8: 1138-1146.

Received 21 March 2007 Accepted 19 July 2007
APPENDIX 1. Plant species detected within each of 5 hay piles at Hays Canyon Range, northwestern Nevada, during sampling on 18 July 2006. Species are listed in order of decreasing abundance (i.e., volume) within each hav pile. The nonnative cheatgrass (Bromus tectorum) appears in bold in the lists below, because it had not been previously reported from pika-created hay piles. At that time of the year, the volume of hay piles approximated the volume of 1.0-2.5 loaves of (conventional white) bread. These data were collected on 18 July 2006; pikas were well along in their haying on 15 June 2006.

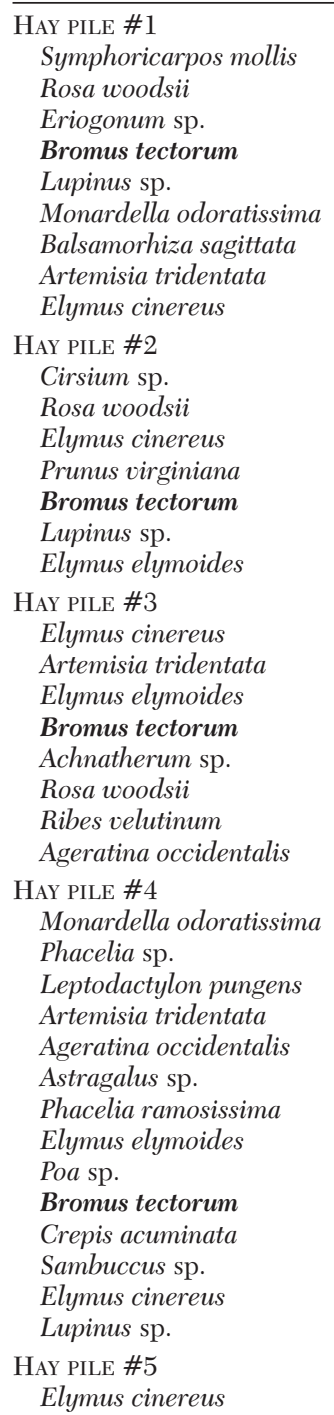

APPENDIX 1 continued.

Monardella odoratissima

Elymus elymoides

Rosa woodsii

Bromus tectorum

Ageratina occidentalis

Balsamorhiza sagittata

Cirsium sp.

APPENDIX 2. Plant species detected near sampled taluses at Hays Canyon Range, northwestern Nevada, during sampling on 18 July 2006. Species are grouped by life-form, following taxonomy and life-forms of the USDA NRCS PLANTS database (Available from: http://plants.usda.gov/). No cushion plants or nonvascular plants were observed.

FORBS

Ageratina occidentalis

Astragalus sp.

Balsamorhiza sagittata

Cirsium sp.

Crepis acuminata

Cryptantha sp.

Eriogonum sp.

Linum sp.

Lupinus sp.

Monardella odoratissima

Phacelia sp.

Phacelia ramosissima

GRAMINOIDS

Achnatherum sp.

Bromus tectorum

Elymus cinereus

Elymus elymoides

Poa sp.

- Pseudoroegneria spicata

SHRUBS

Artemisia tridentata

Chrysothamnus nauseosus

Chrysothamnus viscidiflorus

Leptodactylon pungens

Purshia tridentata

Ribes cereum

Ribes velutinum

Rosa woodsii

Sambucus sp.

Symphoricarpos mollis

Trees

Juniperus occidentalis

Prunus virginiana 